\title{
Reprodução do pirá-brasília, Simpsonichthys boitonei Carvalho (Cyprinodontiformes, Rivulidae), e caracterização de seu habitat na Reserva Ecológica do Instituto Brasileiro de Geografia e Estatística, Brasília, Distrito Federal, Brasil
}

\author{
Oscar A. Shibatta \\ Museu de Zoologia, Departamento de Biologia Animal e Vegetal, Centro de Ciências Biológicas, Universidade Estadual de \\ Londrina.86051-970 Londrina, Paraná, Brasil. E-mail: shibatta@uel.br
}

\begin{abstract}
Reproduction of pira-brasília, Simpsonichthys boitonei Carvalho (Cyprinodontiformes, Rivulidae) and its habitat characterization in the Reserva Ecológica do Instituto Brasileiro de Geografia e Estatística, Brasilia, Distrito Federal, Brazil. This study aims to analyze the reproduction and the physical and chemical characteristics of the habitat of Simpsonichthys boitonei Carvalho, 1959, a rare and endemic species of Distrito Federal. The fish were collected with sieve in a temporary pool located in the Reserva Ecológica do Instituto Brasileiro de Geografia e Estatística (RECOR), rio Taquara basin, Distrito Federal. The specimens were measured (total length in $\mathrm{mm}$ ), weighted (total weight, feminine gonad weight and body weight in grams), for calculation of condition factor (K), gonad-somatic index (IGS) and gonad index (IG). Physical and chemical analyses of environment were also made. The temporary pool was filled with water for eight months (December to August), with total transparency, depth not surpassing $25 \mathrm{~cm}$, conductivity smaller than $15 \mu \mathrm{S} / \mathrm{cm}$ and $\mathrm{pH}$ among 4,70 to 5,11. The dissolved oxygen varied among 2,60 to $4,15 \mathrm{ppm}$, and the temperature of the water among 20 to $25,5^{\circ} \mathrm{C}$. The analysis of reproduction evidenced that the fish has fractional spawning, whose adult females stay with high condition factor during great part of life, but decreasing with their age. The eggs were deposited in the substratum, and the incubation period varied among 55 to 100 days. In laboratory these eggs were maintained in water, where $15,4 \%$ complete the embryonic development. The proportion of females was significantly larger than males. For the characteristics above, we can infer that at least two generations of pirá-brasilia can be found in the same flood period.

KEY WORDS. Annual fish, lyre-finned pearlfish, temporary pool, limnology, reproduction.
\end{abstract}

RESUMO. Este trabalho teve como objetivo analisar a reprodução e as características físicas e químicas do habitat de Simpsonichthys boitonei Carvalho, 1959, uma espécie rara e endêmica do Distrito Federal. Os peixes foram coletados com peneira em uma poça temporária localizada na Reserva Ecológica do Instituto Brasileiro de Geografia e Estatística (RECOR), bacia do rio Taquara, Distrito Federal. Os exemplares foram medidos (comprimento total em $\mathrm{mm}$ ) e pesados (peso total, peso das gônadas femininas e peso do corpo em gramas) para o cálculo do fator de condição (K), do índice gonado-somático (IGS) e do índice gonadal (IG). Também foram feitas análises físicas e químicas do ambiente. $\mathrm{O}$ brejo permaneceu com água durante oito meses (de dezembro a agosto), com transparência total, profundidade não ultrapassando $25 \mathrm{~cm}$, condutividade menor que $15 \mu \mathrm{S} / \mathrm{cm}$ e pH entre 4,70 a 5,11 . $O$ oxigênio dissolvido variou entre 2,60 a $4,15 \mathrm{ppm}$, e a temperatura da água entre 20 a $25,5^{\circ} \mathrm{C}$. A análise da reprodução evidenciou que são peixes de desova parcelada, cujas fêmeas adultas permanecem com fator de condição alto durante boa parte da vida, diminuindo à medida que envelhecem. Os ovos foram depositados no substrato, e o período de incubação variou de 55 a 100 dias. Em laboratório esses ovos foram mantidos em água, onde $15,4 \%$ completaram o desenvolvimento embrionário. A proporção de fêmeas foi significativamente maior que a de machos. Pelas características acima, pode-se inferir que duas gerações do pirá-brasília podem ser encontradas no mesmo período de inundação.

PALAVRAS CHAVE. Limnologia, peixes anuais, pirá-brasília, poças temporárias, reprodução.

O pirá-brasília, Simpsonichthys boitonei, é um peixe raro e endêmico do Distrito Federal, considerado como um "peixe-anual" por viver em poças temporárias e ter seu ciclo de vida completo em aproximadamente um ano. Os ovos dos peixes-anuais sobrevi- vem à dessecação do ambiente por permanecerem enterrados no substrato e com o desenvolvimento embrionário temporariamente suspenso (Wourms 1972). Com o aumento do nível da água, o desenvolvimento embrionário retorna, os indivíduos nascem, 
crescem e, segundo observações em cativeiro (KADLEC 1986), atingem a idade adulta com cerca de dois meses de idade. Apresentam acentuado dimorfismo sexual, sendo os machos avermelhados com listras e pintas azuis iridescentes no tronco e nas nadadeiras, e as fêmeas com coloração castanho-clara com faixas castanho-escuras e uma ou duas manchas negras no meio do tronco (Costa 1995, Costa 2002). A dieta onívora, composta por micro-crustáceos, insetos e algas (Sнibatтa \& Rocha 2001), certamente contribui para o seu rápido crescimento.

Mais recentemente, as espécies $S$. zonatus (Costa \& Brasil, 1990) e S. santanae (Shibatta \& Garavello, 1992) foram descritas para o Brasil Central e que, segundo Costa (1996), seriam espécies irmãs de $S$. boitonei.

Poucos são os estudos ecológicos e biológicos com esta espécie, embora existam vários artigos sobre sua manutenção e reprodução em aquário (KADLEC 1986, KaTz 1979). Além da importância como peixe ornamental, destaca-se pelo fato de estar ameaçada de extinção devido à drenagem, desmatamento e poluição de seu ambiente natural, sendo sua conservação dependente da manutenção de áreas de proteção ambiental (CosTA 2002). Em função dessas ações antrópicas deletérias, provavelmente está extinto em sua localidade tipo, na região do atual Jardim Zoológico de Brasília.

Conhecer as características biológicas e do hábitat de uma espécie são extremamente importantes para sua preservação. Além disso, segundo Nico \& TAPHORN (1984), o ambiente de poças temporárias tropicais é provavelmente o ecossistema de água doce menos estudado. Nesse sentido, a seguir serão apresentados resultados sobre a qualidade física e química do ambiente, além das características reprodutivas da espécie $S$. boitonei.

\section{MATERIAL E MÉTODOS}

A Reserva Biológica do Instituto Brasileiro de Geografia e Estatística (RECOR), fica situada cerca de $35 \mathrm{~km}$ ao sul de Brasília, a $15^{\circ} 56^{\prime}$ S e $47^{\circ} 53^{\prime} \mathrm{W}$, e tem uma área de 1260 ha, com altitude mínima de 1048 m e máxima de 1150 m (Pereira et al. 1992). Nela encontram-se as principais formas da vegetação e da fauna do cerrado. Na reserva originam-se os córregos Roncador, Pitoco, Monjolo, Escondido e Taquara, tributários do riacho do Gama, um dos principais subsidiários do lago Paranoá que, por sua vez, pertence à bacia do rio São Bartolomeu. Nesta área os brejos localizam-se freqüentemente em cabeceiras e nascentes de córregos, ou nas margens de matas ciliares, mas a espécie $S$. boitonei ocorre apenas no brejo da Cerca, próximo ao ribeirão Taquara.

Na região do Cerrado, duas estações são bem nítidas: uma chuvosa e quente (outubro a abril), com concentração de chuvas entre novembro a março, e outra fria e seca (maio a setembro), com os meses mais secos entre junho a agosto (NIMER 1989). Segundo a classificação climática de Köppen, o clima situa-se entre o tropical de savana (Aw) e o temperado chuvoso de inverno seco (Cwhl). O solo característico é o laterítico (latossolos vermelhos ou vermelho-amarelados), de $\mathrm{pH}$ ácido e de baixa fertilidade (CoDePLAN/GdF 1984).
Um total de 102 exemplares (46 machos e 56 fêmeas) foi coletado com peneira (malha de $1 \mathrm{~mm}$ entre nós adjacentes), no período de abril de 1986 a abril de 1988, em sete expedições de coleta. Alguns exemplares foram fixados em formol a $10 \%$ por $24 \mathrm{~h}$ e preservados em álcool a 70\% para obtenção do comprimento $(\mathrm{mm})$, peso do corpo e das gônadas (g). Nove casais foram mantidos vivos em aquários no laboratório de Ecologia da Universidade de Brasília (UnB), para as desovas. Foram feitas análises físicas e químicas da água do ambiente de coletas, que compreenderam: o seu nível em centímetros, a transparência (disco de Secchi), a condutividade (condutivímetro YSI 33), o oxigênio dissolvido (oxímetro YSI 54A), a temperatura (sensor de temperatura acoplado ao YSI 33 ou YSI 54A) e o pH (medido com potenciômetro Micronal).

A razão sexual foi testada para o total de peixes capturados, aplicando-se o teste de aderência Chi-quadrado (SIEgeL 1975) considerando-se como 50\% a freqüência esperada para cada sexo. Foram calculados o fator de condição de Fulton $\left[\mathrm{K}=\left(\mathrm{Wt} / \mathrm{Lt}^{3}\right) .10\right.$ onde $\mathrm{Wt}=$ peso do corpo $(\mathrm{g})$ e $\mathrm{Lt}=$ comprimento total $(\mathrm{mm})]$, o índice gonadal $\left[\mathrm{IG}=\left(\mathrm{Wg} / \mathrm{Lt}^{3}\right) .100\right.$ onde $\mathrm{Wg}=$ peso das gônadas $(\mathrm{g})]$ e o índice gonado-somático (IGS $=\mathrm{Wg} / \mathrm{Wt}$ ), conforme VAzzoler (1981), com 28 exemplares coletados em julho de 1987, março e abril de 1988. Justifica-se o pequeno número de amostras por serem peixes raros e pelo ambiente não apresentar água durante o ano inteiro. A diferença dos valores médios de cada amostra foi testada com a análise de variância (ANOVA com uma fonte de variação), no nível de significância de 5\%, utilizando-se o programa PAST (HAMmer et al. 2001).

Para acompanhar o tempo de duração do desenvolvimento embrionário, nove casais foram colocados separadamente para desovar em um aquário de $10 \mathrm{l}$ de capacidade, com substrato de pó-de-xaxim. Os ovos foram coletados após três dias com uma pipeta e mantidos separadamente, à temperatura ambiente, em pequenos frascos de $80 \mathrm{~mL}$ de capacidade, contendo água do aquário de origem (cujas características químicas eram similares às do ambiente natural), e um bactericidafungicida a base de sulfanilamida, azul de metileno e formaldeído. As etapas do desenvolvimento embrionário foram identificadas segundo Wourms (1972).

\section{RESULTADOS}

O ambiente natural era formado por duas poças de água interligadas, com aproximadamente quatro metros de extensão cada, rasas, com profundidades máximas variando entre 18 a 25 $\mathrm{cm}$, que na época de cheia se ramificavam em direção ao ribeirão Taquara. Havia densa quantidade da turfa Sphagnum sp., Mayaca sellowiana Kunth, 1843, algas filamentosas, além de folhas e galhos. As poças estavam cheias em todas as datas de coleta, com exceção de outubro de 1987, quando secaram completamente (Tab. I). Também foi observado que permaneceram cheias durante oito meses, no período de dezembro de 1986 a agosto de 1987.

Revista Brasileira de Zoologia 22 (4): 1146-1151, dezembro 2005 
Tabela I. Número de amostras, data, número de exemplares machos e fêmeas coletados e características físicas e químicas da água do brejo da Cerca, Reserva Ecológica do Instituto Brasileiro de Geografia e Estatística, Brasília, Distrito Federal. (OD) Oxigênio dissolvido, (T) temperatura em graus Celsius, $(\mu S)$ micro Siemens, $(\mathrm{pH})$ potencial hidrogeniônico, (DP) desvio padrão, (CV) coeficiente de variação.

\begin{tabular}{|c|c|c|c|c|c|c|c|}
\hline Amostra & Data & Machos $(n=46)$ & Fêmeas $(n=56)$ & OD (ppm) & $\mathrm{T}\left({ }^{\circ} \mathrm{C}\right)$ & Condutividade $(\mu \mathrm{S} / \mathrm{cm})$ & $\mathrm{pH}$ \\
\hline 1 & 11.IV.1986 & 5 & 3 & 4,00 & 24,0 & 15 & 4,70 \\
\hline 2 & 26.VIII.1986 & 3 & 5 & 3,20 & 20,0 & - & 5,00 \\
\hline 3 & 06.V.1987 & 6 & 14 & 3,20 & 25,5 & 10 & 5,31 \\
\hline 4 & 03.VII.1987 & 13 & 16 & 2,60 & 23,0 & 5 & 5,11 \\
\hline 5 & $08 . X .1987^{*}$ & - & - & - & - & - & - \\
\hline 6 & 10.III.1988 & 6 & 9 & 4,25 & 24,0 & 0 & - \\
\hline 7 & 27.IV.1988 & 13 & 9 & - & - & - & - \\
\hline Média \pm DP & & $6,57 \pm 4,86$ & $8 \pm 5,77$ & $3,45 \pm 0,67$ & $23,3 \pm 2,05$ & $7,5 \pm 6,45$ & $5,03 \pm 0,25$ \\
\hline CV (\%) & & 74 & 72 & 19,39 & 8,8 & 86,06 & 5,1 \\
\hline
\end{tabular}

* Brejo seco, (-) dados não registrados.

O brejo era circundado por vegetação representada por Pteridófitas, Briófitas, Eriocaulaceae Desvaux, 1828, Alismataceae Vent., 1799, Drosera Linnaeus, 1753, além do buriti Mauritia vinifera Martius, 1824. Mais acima, onde medravam as águas que mantinham o brejo cheio, havia um campo úmido rico em Cyperacea de Jussieu, 1789 e Poaceae Barnhart, 1895.

Quanto às variáveis físicas e químicas da água, a transparência foi total. A condutividade foi menor que $15 \mu \mathrm{S} / \mathrm{cm}$ (média $=7,5$, desvio padrão $=6,45)$. O oxigênio dissolvido foi de 2,60 a 4,25 ppm (média $=3,45, \mathrm{~s}=0,67$ ). A temperatura variou de 20 a $25,5^{\circ} \mathrm{C}$ (média $=23,3, \mathrm{~s}=2,05$ ). A correlação entre a temperatura e a concentração de oxigênio foi baixa $\left(r^{2}=0,27\right)$. $\mathrm{O}$ pH do ambiente estudado também foi relativamente baixo $(4,70$ a 5,31 , média $=5,03, \mathrm{~s}=0,25)$ (Tab. I).

Outros peixes coletados nessas poças foram o rivulídeo Rivulus pictus Costa, 1989, e o caracídeo Astyanax scabripinnis (Jenyns, 1842).

Em seis amostras foram coletados 102 exemplares adultos (média de 17 peixes por coleta) sendo 46 machos e 56 fêmeas. Aplicando-se o teste do Qui-quadrado $\left(\chi^{2}\right)$ foi possível observar que as proporções sexuais diferem, sendo o número de fêmeas mais elevado que o de machos $\left(\chi^{2}=49,35, \alpha=0,05\right)$.

Estes peixes possuem desova parcelada evidenciada pela análise dos ovócitos de 16 fêmeas coletadas nos meses de março, abril e julho. Todas apresentavam ovócitos de vários tamanhos com os maiores dispostos mais posteriormente dentro do ovário e os menores mais anteriormente e internamente. Além disso, desovaram em cativeiro assim que foram colocadas com um macho, mesmo sendo coletadas em épocas diferentes.

Um total de 84 ovos foi obtido de nove casais, com o número variando de 2 a 15 ovos por casal (média $=9,33$, $S=5,85235$ ). Considerando que esses ovos foram coletados após três dias do casal ser colocado para a reprodução, cada fêmea poderia ter produzido cerca de três ovos por dia. Os ovos, de aproximadamente $1,6 \mathrm{~mm}$, possuem uma membrana com consistência rígida e várias papilas. Desses ovos, cerca de 46\% ini- ciaram o desenvolvimento, mas outros logo ficavam opacos e não se desenvolviam. Apenas $12(15,4 \%)$ atingiram o final do desenvolvimento embrionário, chegando à eclosão.

Até os vinte dias de idade os embriões desenvolveram-se muito lentamente. Nessa ocasião, ainda estavam na fase do somito longo ou mesmo na de células dispersas. Aos quarenta dias já apresentam pigmentação e circulação sangüínea, movimentavam os olhos e contraíam o corpo. A partir de então, os embriões desenvolveram as nadadeiras peitorais e aumentaram o número de cromatóforos. Apesar de pertencerem a uma mesma desova, nasceram em dias separados, variando de 55 a 100 dias de incubação. Ao nascerem, os filhotes possuíam entre 4,15 a $5,10 \mathrm{~mm}(\mathrm{n}=7$, média $=4,54$, desvio $=0,31)$. Nesta fase já estavam aptos a nadar, embora a nadadeira dorsal ainda não estivesse desenvolvida.

A ANOVA permitiu interpretar que o fator de condição foi significativamente semelhante entre as três coletas analisadas tanto para fêmeas quanto para machos, ao nível de significância de $5 \%\left(\mathrm{~F}_{\text {machos }}=3,797, \mathrm{p}=0,06 ; \mathrm{F}_{\text {fêmeas }}=0,6453, \mathrm{p}=0,54\right)$. $\mathrm{O}$ índice gonadal das fêmeas foi menor no mês de março, e maior em abril e julho, o mesmo acontecendo com o índice gônado-somático (Tab. II). Essas diferenças foram significativas entre as amostras, conforme pode ser observado pela ANOVA $\left(\mathrm{F}_{\mathrm{IG}}=31,08, \mathrm{p}=0,0000298 ; \mathrm{F}_{\mathrm{IGS}}=31,95, \mathrm{p}=0,0000262\right)$. No entanto, na coleta de agosto de 1986, as fêmeas não apresentavam aspecto físico satisfatório, sendo que muitas delas morreram durante o transporte para o laboratório.

\section{DISCUSSÃO}

As poças onde $S$. boitonei foi coletado localizavam-se em um campo graminoso úmido natural, que difere ligeiramente do "Brejo de Ludwigia", que é o brejo mais comum no Distrito federal (EITEN 1978), por estar numa área de transição entre a vereda e a mata ciliar. Por isso possui vegetação que pertencem aos dois tipos de ambientes, isto é, Poaceae, Cyperaceae e buritis 
Tabela II. Valores médios e respectivos desvios padrão do fator de condição (K), índice gonadal (IG) e índice gônado-somático (IGS) em machos e fêmeas de $S$. boitonei.

\begin{tabular}{|c|c|c|c|c|c|c|}
\hline \multirow{2}{*}{ Data da coleta } & \multicolumn{3}{|c|}{ Machos } & \multicolumn{3}{|c|}{ Fêrmeas } \\
\hline & 03.VII.1987 & 10.III.1988 & 27.IV.1988 & 03.VII.1987 & 10.III.1988 & 27.IV.1988 \\
\hline $\mathrm{N}$ & 5 & 4 & 4 & 5 & 7 & 3 \\
\hline$K(x 10-4)$ & $1,10 \pm 0,104$ & $1,16 \pm 0,038$ & $1,24 \pm 0,036$ & $1,39 \pm 0,184$ & $1,43 \pm 0,133$ & $1,51 \pm 0,118$ \\
\hline IG $(x 10-4)$ & - & - & - & $21,21 \pm 0,88$ & $0,738 \pm 3,60$ & $16,47 \pm 2,51$ \\
\hline IGS & - & - & - & $0,185 \pm 0,032$ & $0,053 \pm 0,025$ & $0,123 \pm 0,021$ \\
\hline
\end{tabular}

da vereda e arbustos e árvores da mata ciliar. A faixa que compreende este ambiente varia de alguns metros até algumas dezenas de metros de largura em vales diferentes. O lençol freático aproxima-se e permanece perto da superfície durante o período de chuvas, ou a água pode aflorar na parte inferior da encosta e correr em película fina sobre a superfície. Segundo CosтА (2002) esse tipo de ambiente é atípico se comparado aos daqueles de outras espécies.

Carvalho (1964), relatou a presença de espécies de Rivulus e Astyanax de cauda avermelhada na localidade tipo do pirábrasília, que provavelmente pertencem às mesmas espécies coletadas no Brejo da Cerca da RECOR. Devido ao fato de Rivulus e Astyanax não pertencerem à categoria dos peixes anuais, a presença dessas espécies no brejo deve-se aos seus deslocamentos através dos filetes de água que conectam as poças ao ribeirão Taquara. É provável que o brejo seja um excelente fornecedor de alimentos e abrigos, necessários à sobrevivência de juvenis dessas espécies. Para que ocorra a convivência das três espécies, existe uma diferença quanto à ocupação espacial na coluna d'água, sendo o pirá-brasília encontrado nos estratos inferiores, Astyanax à meia profundidade e Rivulus mais à superfície (SніватTA \& Bennemann 2003). Segundo Nico \& TAPHorn (1984), o ambiente de poças temporárias tropicais serve de moradia tanto para os peixes anuais, como para insetos e anfíbios.

As espécies do Brasil Central, S. boitonei, $S$. zonatus e $S$. santanae não ocorrem em sintopia, como pode ser depreendido de Carvalho (1959), Costa \& Brasil (1990) e Shibatta \& Garavello (1992). Entretanto, em outras regiões do continente existem poças multiespecíficas, abrigando, inclusive gêneros diferentes de peixes anuais que apresentam padrões comportamentais distintos que não permitem o cruzamento entre essas espécies, como ocorre com Cynopoecilus melanotaenia (Regan, 1912), Austrolebias viarius (Vaz-Ferreira, Sierra \& Scaglia, 1964) e Austrolebias luteoflamulatus (Vaz-Ferreira, Sierra \& Scaglia, 1964), ou de Austrolebias bellotti (Steindachner, 1881) e Austrolebias nigripinnis (Regan, 1912) no Uruguai (VAz-FERreIra \& SIERRA 1973).

A condutividade da água foi relativamente baixa nas poças onde $S$. boitonei foi coletado, provavelmente devido ao fato das águas que abastecem as poças serem provenientes das chuvas e do subsolo relativamente pobre em íons do Distrito Federal (CoDEPLAN/GDF 1984). Embora os valores de condutividade sejam evidências de pobreza de íons dissolvidos na água, o coeficiente de variação calculado variou consideravelmente de um período para outro, o que pode ser conseqüência do maior ou menor aporte de água nesses períodos.

A concentração de oxigênio dissolvido apresentou-se em níveis inferiores à de outros ambientes aquáticos do Distrito Federal como, por exemplo, o lago Paranoá (Altafin et al. 1995). Como as coletas foram realizadas no período de 9:00 às 10:00 $\mathrm{h}$, isso deve ter contribuído para os baixos níveis de OD, uma vez que a sua concentração é mais baixa durante a noite, como foi verificado por Nico \& TAPHORN (1984) em brejos estacionais da Venezuela, quando plantas cessam o processo fotossintético.

A temperatura apresentou pouca variação, e a correlação entre a temperatura e a concentração de oxigênio dissolvido foi baixa, evidenciando que neste ambiente a relação entre essas variáveis é complexa. Esperava-se uma correlação maior, mas outros fatores, como a fotossíntese, podem ter interferido nas concentrações de OD.

$\mathrm{O}$ pH do ambiente estudado também é relativamente baixo o que diverge das informações de BAstos (1984) que apresenta uma variação entre 6,9 a 7,2, para outros locais onde $S$. boitonei foi encontrado. A outra espécie de Simpsonichthys do Distrito Federal, $S$. santanae, vive em um ambiente semelhante ao de S. boitonei, com OD entre 2,7 a 5,4 ppm; temperaturas entre 17 a $19^{\circ} \mathrm{C}, \mathrm{pH}$ de 5,4 e profundidade máxima de $20 \mathrm{~cm}$ (Shibatta \& Garavello 1992). A região de Brasília, de acordo com dados do IbDF (1979) repousa sobre uma velha estrutura de rochas metamórficas pré-Cambrianas ou Eupaleozóicas, tratando-se portanto de uma plataforma afetada por intrusões ácidas.

As características físicas e químicas da água, disponíveis neste trabalho, não permitem fazer uma correlação rigorosa com as características biológicas, mas é possível supor que a secagem do substrato não é fator limitante para o desenvolvimento de alguns ovos, pois mesmo sem o período de desidratação ocorreu a eclosão. O mesmo fenômeno relacionado ao desenvolvimento embrionário foi observado por Katz (1979). Peter (apud Wourms 1972) acredita que é o aumento da concentração de oxigênio que quebra o estado de quiescência dos embriões. De maneira simplista poderíamos supor que, com a seca do brejo, o oxigênio circulante diminui com a compactação do solo e, com o advento da cheia, os níveis de oxigênio devem aumentar com a descompactação desse solo e com o

Revista Brasileira de Zoologia 22 (4): 1146-1151, dezembro 2005 
restabelecimento da flora aquática. Mas os mecanismos de oxigenação do brejo são complexos, pois ao contrário do que se possa imaginar, mesmo na seca pode ocorrer aeração das camadas mais profundas do substrato e, conseqüentemente, a dos ovos. Lowe-McConnell (1999) explica que o ar chega até os ovos por expansão e contração do lodo seco, causadas pelas flutuações diurnas de temperatura. Além disso, foi verificado por Scheel (apud Lowe-Macconell 1999) que o solo submerso pode apresentar condições anaeróbicas, onde os ovos depositados por Austrolebias nigripinnis podem permanecer viáveis mesmo depois de três anos.

Segundo SCHÄFER (1985), as baixas concentrações de oxigênio dissolvido e do $\mathrm{pH}$ dificultam a proliferação de bactérias. Provavelmente, este fato contribui para a lenta decomposição do material vegetal, o que é típico de turfeiras, fornecendo maior proteção aos ovos enterrados no substrato.

Papilas nas membranas dos ovos também foram observadas em Nematolebias whitei (Myers, 1942) por CARvalHo (1957), que identificou dois tamanhos diferente, os menores entremeando os maiores.

Período semelhante de incubação dos ovos para a espécie foi observado por KADLEC (1986), entre 60 a 100 dias. O fato de nascerem em diferentes períodos, mesmo pertencendo à mesma desova, foi verificado por Wourms (1972) em Nematolebias whitei e Cynopoecilus melanotaenia e denominado de "efeito multiplicador". Trata-se de uma estratégia necessária para manter um estoque populacional sempre disponível para que a espécie sobreviva às variações ambientais mais rigorosas. Com isso os filhotes não nascem ao mesmo tempo, evitando que todos se percam em condições ambientais inadequadas à sobrevivência (WoOTTON 1990).

O número de fêmeas mais elevado que o de machos pode estar relacionado com o fato dos machos serem territoriais. O ambiente de poças limita o número de machos que defendem um determinado espaço e restringe a presença de outros nas proximidades, enquanto um maior número de fêmeas estão livres para percorrer vários territórios. Embora não seja regra, machos agressivos têm sido verificados com maior freqüência em espécies políginas (MaGURRAN \& GarCia 2000), como é o caso de $S$. boitonei.

O fator de condição semelhante nos exemplares das três coletas analisadas sugere que durante esses períodos mantêmse sempre em condições adequadas para reprodução e desovam até bem próximo da seca do brejo. Estas observações contradizem KADLEC (1986), que menciona um período de desovas muito curto, de abril a maio.

Desta forma, é possível avaliar que, embora $S$. boitonei não se encontre em ambientes perenizados, alguns de seus ovos eclodem mesmo com a manutenção do nível da água. Com as informações obtidas, é possível inferir que podem ocorrer pelo menos duas gerações num mesmo período de alagamento. Além disso, devido ao "efeito multiplicador", desovas em diferentes ocasiões aumentam a possibilidade de sobrevivência da espécie às depleções prolongadas e estocásticas do nível da água.

\section{AGRADECIMENTOS}

O autor agradece a Antonio José Andrade Rocha, da Universidade Católica de Brasília, pelas orientações iniciais do trabalho; a Jader Soares Marinho Filho da Universidade de Brasília e Ivan Sazima da Universidade de Campinas, pela leitura crítica do primeiro manuscrito. Ao Dr. Heitor Frossard, da UEL, pela correção do texto e discussões limnológicas. Ao Manuel Paiva do Herbário da UEL, pelo auxílio às questões botânicas. A Christina Wiss Castelo Branco e Carmen Silvia Menezes e ao técnico Mardocheu Pereira Rocha pelo auxílio nas coletas de campo. Ao Mauro Ribeiro da Reserva Ecológica do IBGE, pelas permissões de coleta. O autor recebeu bolsa IC do CNPq, Proc. 102177/87-2, para o desenvolvimento do trabalho.

\section{REFERÊNCIAS BIBLIOGRÁFICAS}

Altafin, I.G.; S.P. Mattos; C.G.B. Cavalcanti \& V.R. Estuqui. 1995. Paranoá lake - Limnology and recovery program, p. 325349. In: J.G. Tundisi; C.E.M. Bicudo \& T. Matsumura-Tundisi (Eds). Limnology in Brazil. Rio de Janeiro, Academia Brasileira de Ciências, Sociedade Brasileira de Limnologia, 376p.

Bastos, E.K. 1984. Cynolebias boitonei, in Zentralbrasilien beobachtet. Das Aquarium, Bornheim, 18 (1777): 119-123.

Carvalho, A.L. 1957. Notas para o conhecimento da biologia dos peixes anuais. Revista brasileira de Biologia, Rio de Janeiro, 17 (4): 459-466.

Carvalho, A.L. 1959. Novo gênero e nova espécie de peixe anual de Brasília, com uma nota sobre os peixes anuais da baixada fluminense, Brasil. Boletim do Museu Nacional, Rio de Janeiro, 201: 1-10.

Carvalho, S. 1964. The new Brasilia lyrefin. Tropical Fish Hobbyist, Neptune City, 13: 5-13.

Codeplan/GdF. 1984. Atlas do Distrito Federal II. Brasília, Governo do Distrito Federal, 383p.

Costa, W.J.E.M. \& G.C. Brasil. 1990. Description of two new annual fishes of the genus Cynolebias (Cyprinodontifomres: Rivulidae) from the São Francisco basin, Brazil. Ichthyological Exploration of Freshwaters, München, 1: 15-22.

Costa, W.J.E.M. 1995. Pearl killifishes: the Cynolebiatinae. New Jersey, TFH Publications, 128p.

Costa, W.J.E.M. 1996. Phylogenetic and Biogeographic analysis of the Neotropical annual fish genus Simpsonichthys (Cyprinodontiformes: Rivulidae). Journal of Comparative Biology, Ribeirão Preto, 1 (3/4): 129-140.

CostA, W.J.E.M. 2002. Peixes anuais brasileiros: diversidade e conservação. Curitiba, Editora da Universidade Federal do Paraná, 238p.

EITEN, G. 1978. Delimitation of cerrado concept. Vegetatio, Bangor, 36 (3): 169-178.

Hammer, Ø.; D.A.T. Harper \& P.D. Ryan. 2001. PAST: Palaeontological statistics software package for education and data analysis. Palaentologia Electrônica, 4 (1): 1-9. Available on line at http://palaeo-electronica.org. 
IbDf. 1979. Plano de Manejo, Parque Nacional de Brasília. Brasília, Documento Técnico $\mathrm{n}^{\circ} 2,98 \mathrm{p}$.

KaDleC, J. 1986. The lyre-finned pearlfish: Cynolebias boitonei. Tropical Fish Hobbyist, Neptune City, 35 (1): 70-73.

Katz, D. 1979. Experience with Simpsonichthys boitonei. Journal of American Killifish Association, New York, 12 (1): 19-23.

Lowe-McConnell, R.H. 1999. Estudos ecológicos de comunidades de peixes tropicais. São Paulo, Edusp, 534p.

Magurran, A.E. \& C.M. Garcia. 2000. Sex differences in behaviour as an indirect consequence of mating system. Journal of Fish Biology, London, 57: 839-857.

Nico L.G. \& D.C. TAPHORN. 1984. Limnology of Orinoco basin Annual killifish pools. Journal of American Killifish Association, New York, 19 (2): 59-72.

Nimer, E. 1989. Clima, p. 23-34. In: Instituto Brasileiro de GeograFia e Estatística (Ed). Geografia do Brasil: Região Centro-Oeste. Rio de Janeiro, IBGE, Diretoria de Geociências, vol. 1, 267p.

Pereira, B.A.S.; M.A. Silva \& R.C. Mendonça. 1992. Reserva Ecológica do IBGE, Brasília (DF, Brasil): lista de plantas vasculares. Rio de Janeiro, IBGE, 42p.

SCHÄFER, A. 1985. Fundamentos de Ecologia e Biogeografia das Águas Continentais. Porto Alegre, Editora da Universidade, 532p.

Shibatta, O.A. \& S.T. Bennemann. 2003. Plasticidade alimentar em Rivulus pictus Costa (Osteichthyes, Cyprinodontiformes, Rivulidae) de uma pequena lagoa em Brasília, Distrito Fede- ral, Brasil. Revista Brasileira de Zoologia, Curitiba, 20 (4): 615-618.

Shibatta, O.A. \& J.C. Garavello. 1992. Descrição de uma nova espécie do gênero Cynolebias Steindachner do Brasil Central (Pisces: Cyprinodontiformes). Comunicações do Museu de Ciências da PUCRS, Série Zoologia, Porto Alegre, 5 (11): 179-195.

Shibatta, O.A. \& A.J.A. Rocha. 2001. Alimentação em machos e fêmeas do pira-brasília, Simpsonichthys boitonei Carvalho (Cyprinodontiformes, Rivulidae). Revista Brasileira de Zoologia, Curitiba, 18 (2): 381-385.

SIEGEL, S. 1975. Estatística não-paramétrica para ciências do comportamento. São Paulo, McGraw-Hill, 350p.

Vaz-Ferreira, R. \& B. Sierra. 1973. Caracteres etologicos genéricos y específicos en los peces del gênero Cynolebias Steindachner, 1876. Boletin de la Sociedad Zoologica del Uruguay, Montevideo, 2: 22-35.

VAzzolER, A.E.A.M. 1981. Manual de métodos para estudos biológicos de populações de peixes: reprodução e crescimento. Brasília, CNPq, 106p.

Wootton, R.J. 1990. Ecology of Teleost fishes. London, Chapman and Hall, 404p.

Wourms, J.P. 1972. The developmental Biology of annual fishes III. Pre-embryonic and embryonic diapause variable duration in the eggs of annual fishes. Journal of Experimental Zoology, Hoboken, 182: 389-414.

Recebido em 31.V.2005; aceito em 21.XI.2005. 